\title{
Additive and Non-Additive Genetic Variances for Tree Growth in Several Hybrid Poplar Popu- lations and Implications Regarding Breeding Strategy
}

\author{
W.E. Berguson, B.G. McMahon, and D.E. Riemenschneider
}

Natural Resources Research Institute, University of Minnesota Duluth, 5013 Miller Trunk Highway, Duluth, MN 55811 USA

Corresponding author: e-mail address: bmcmahon@d.umn.edu

\begin{abstract}
Populus species (P. deltoides, P. maximowiczii, P. nigra) and their inter-specific hybrids were tested for growth rate over a five year period at four test locations in Minnesota, USA, to estimate genetic variance components. The breeding scheme incorporated recurrent selection of full-sib families of pure species parents, production of $F_{1}$ inter-specific hybrids from selected families, and selection of clones within the $F_{1}$ s. Improvement of yield through time using this scheme is predicated on the assumption that additive effects comprise a significant portion of the total genetic variance. The estimates of additive and non-additive variances reported are not traditional point estimates, because a fully balanced mating design was impossible due to parental incompatibilities which result in incomplete breeding matrices. Instead, bounded estimates, not previously used in tree genetics research, are derived from linear combinations of formulae of genetic expectations observed amongfamily, among-clone, and environmental variances. Our results suggest that combined family and mass selection would lead to increases in growth rate of $27 \%$ and $47 \%$ per generation in $P$. deltoides and P. nigra, respectively. Broad sense-based clonal selection within the $F_{1}$ could yield selection responses in excess of $90 \%$ of the mean of such populations. Among-family variance comprised about $1 / 3$ of total genetic variance while within-family variance was always about $2 / 3$ of total genetic variance, regardless of pedigree. The results indicate that recurrent intraspecific selective breeding followed by interspecific hybridization and non-recurrent selection based on broad sense genetic variation would constitute an effective yield improvement strategy.
\end{abstract}

Keywords: Populus, breeding strategy, additive and non-additive genetic variance, clonal selection

\section{Introduction}

We present results from our poplar (Populus sp.) breeding research conducted in the state of Minnesota, USA, over approximately a 15 -year period. While the primary goal of our program was the development of new clonal varieties for commercial application, studies were designed to answer important questions relating to heritability of growth rate within these populations. Our breeding strategy has been the creation and testing of $F_{1}$, inter-specific hybrids between native eastern cottonwood (Populus deltoides Marsh.) and other sexually compatible Populus species from the taxonomic sections Aigeiros and Tacamahaca. We pursued an inter-specific breeding strategy because, even though clonally selected intra-specifically hybridized eastern cottonwood trees are capable of rapid growth and possess other desirable qualities, dormant hardwood cuttings of pure eastern cottonwood produce adventitious roots erratically and unreliably when field-planted in northern U.S. soils and climates (Ying and Bagley, 1977; Zalesny Jr. et al., 2005). Hybridization between eastern cottonwood and other species has been shown to increase rootability of the resulting hybrid as compared to the eastern cottonwood parent (Stettler et al., 1992).

Inter-specific hybrid poplar breeding can be pursued in many ways. The variety of options available to the breeder is enumerated in Bisoffi and Gullberg (1996) and Riemenschneider et al. (2001). At the most elementary level, randomly selected parents from wild populations can be mated under controlled conditions followed by clonal testing of the resultant progeny. However, breeding among parents with no prior information on local performance within the region may not be a productive strategy. Given additional time, a more sophisticated approach may be field testing of parental breeding populations in the region of intended commercial deployment followed by inter-specific matings made only among selections with proven superior performance in these field tests. 
Due to limited pre-existing performance data to guide breeding at the beginning of our work, we were not able to employ the putatively more sophisticated approach involving parental development through advanced generation recurrent breeding. Also, our needs were pressing because hybrid poplar was becoming an important feedstock for paper-making in Minnesota, and the deployment of short-rotation woody crops as an energy feedstock seemed likely and imminent. Commercial plantings in Minnesota heavily relied on a single clone, the $P$. nigra x P. maximowiczii hybrid CV. "NM6," previously selected in a regional clone testing program (Hansen et al., 1994; Netzer et al., 2002). Yet, a monoclonal deployment strategy over the long term is considered fraught with risk (Libby, 1982; Zobel and Talbert, 1984; Roberds et al., 1990) and an increase in the genetic diversity of commercial varieties was required.

In addition to the aforementioned considerations, limited knowledge of genetic variances in poplar populations precluded a scientifically sound justification for mounting a strategy of recurrent parental selection followed by hybridization and clonal selection. Clearly, recurrent selection for parental development would rely on strong genetic variability attributable to additive effects; whereas, clonal selection among inter-specific hybrid progeny could take advantage of both additive and non-additive variances (see Mullin and Park, 1992 and references therein for a review of relevant algebraic expressions). The relative magnitudes of additive and non-additive variances in tree growth were unknown yet have a direct bearing on the effectiveness of any hypothesized breeding strategy.

In the current paper, we describe our analyses of genetic variance components within and among several poplar populations and discuss the implications of our results relative to a long-term breeding strategy. Also, we present bounded estimates of the expected increase in tree growth as a result of selection. Our estimates of additive and non-additive variances are not traditional point estimates, because achieving a fully balanced mating design was impossible due to parental incompatibilities which result in incomplete breeding matrices. Instead, we present bounded estimates derived from linear combinations of formulae of genetic expectations observed for among-family, among-clone, and environmental variances. We also investigated the precision with which those variances might be estimated from hypothesized future populations produced under a perfectly balanced experimental design. We briefly discuss the assumptions that underlie genetic variance estimation and the implications of those assumptions relative to our results. Our results have application to others who pursue the genetic improvement and understanding of similar populations.

\section{Material and Methods}

In 1996 we began producing full-sib families of intra- and interspecific hybrid poplars through controlled crossing. Parents were selected from previously established tests of $P$. deltoides open-pollinated (half-sib) families, mostly of Minnesota origin from Dr. Carl Mohn's University of Minnesota collections. Populus nigra male parents were obtained from trees in a field test near Maple, Ontario, established by Dr. Louis Zsuffa and staff at the University of Toronto. Populus maximowiczii parents were obtained from the same source. Branches from male trees were placed in water in isolation chambers where pollen was forced and later sieved and stored. Branches from female trees were placed in containers and kept in a cool growth chamber with bottom heat for 3 to 4 weeks to initiate root formation prior to moving female branches into the greenhouse. This was done to reduce abscission of flowers during the process of pollination and subsequent seed development. Pollinations were performed by brush application, and mature capsules were collected. The number of successful matings differed according to species combination, but success typically ranged between 40 $\%$ and $65 \%$ depending on taxon. Cleaned seed was immediately germinated in containers in the greenhouse. Seedlings were reared until spring and planted in nurseries at Grand Rapids, Minnesota and Belle River, Minnesota. Dormant hardwood mini-cuttings $(7.5$ to $10.0 \mathrm{~cm}$ in length with at least two viable buds) were collected from seedlings and planted in containers in the greenhouse. Emergent shoots were grown indoors for a period of 8-10 weeks and moved outdoors to acclimate prior to field planting.

This paper reports results of four separate field tests established in 2001, 2002, 2007 and 2008. These experiments employed a design comprising randomized complete blocks with a single ramet of each genotype per replication at 3.3 meter $\times 3.3$ meter spacing. These tests were established using operational management practices on commercial plantations intended for pulpwood production. Thirty genotypes per family were clonally propagated and planted as single-tree plots in replicated complete blocks ranging from three to five replications per site. We produced and field tested 40 full-sib families of $P$. deltoides $x$ P. deltoides, 28 full-sib families of $P$. deltoides $x P$. maximowiczii, 41 full-sib families of $P$. deltoides $x$ P. nigra, and 40 full-sib families of various $F_{2}$ and first-generation backcross advanced-generation pedigrees.

We have also assembled and tested a large population of Populus nigra. We obtained open-pollinated seed collections from throughout the European range of the species from Italy in the south to Belgium and Germany in the north with a west to east range extending from France to Turkey. We reared 38 families and 2,712 progeny or seedlings which were clonally replicated and established in field tests as described above. Tree diameters ( $\mathrm{dbh}=$ diameter at 1.37 meters) were measured at age 5 years to the nearest $0.1 \mathrm{~cm}$ and converted to basal area to the nearest $0.1 \mathrm{~cm}^{2}$. Basal area data were used in analyses of variance because cross sectional area is linearly related to tree volume and mass (Miller, 2016). In total, more than 4,000 clonally replicated genotypes were tested amounting to over 10,000 trees at four test locations measured over a five-year period.

Populations of full-sib intra and inter-specific families were subjected to analysis of variance according to the model:

$$
X_{i j k l m}=T_{i}+R(t)_{i j}+F(T)_{i j k}+C(F)_{i j k l}+e_{i j k l m}
$$

where: $\mathrm{X}_{\mathrm{ijk} \mathrm{km}}$ is an observation made in the $\mathrm{i}^{\text {th }}$ location, in the $\mathrm{j}^{\text {th }}$ replication within the $\mathrm{i}^{\text {th }}$ location, on the $\mathrm{k}^{\text {th }}$ family within the $\mathrm{i}^{\text {th }}$ 
location, on the $\mathrm{t}^{\text {th }}$ clone within the $\mathrm{k}^{\text {th }}$ family and the $\mathrm{m}^{\text {th }}$ ramet within the ${ }^{\text {th }}$ clone.

Age five basal area of trees in the Populus nigra population was also subjected to analysis of variance according to the single test location model:

$$
X_{i j k l m}=R(t)_{i}+F_{j}+C(F)_{j k}+e_{i j k l}
$$

Where: $\mathrm{X}_{\mathrm{ijkl}}$ is an observation made in the $\mathrm{i}^{\text {th }}$ replication on the $j^{\text {th }}$ family, on the $k^{\text {th }}$ clone within the $j^{\text {th }}$ family and the $k^{\text {th }}$ ramet within the $\mathrm{k}^{\text {th }}$ clone.

Analyses of variance and estimation of components of variance attributable to various model-specified effects were made using Type I observed mean squares and expected mean squares. Preliminary examination of results indicated little meaningful differences between Type I versus Type III estimation or any other analysis or estimation procedures. All analyses were conducted using SAS procedures GLM and VARCOMP Version 9.1 (SAS Institute, Inc., 2004).

Estimation of variances due to additive and non-additive genetic effects was problematic because our analysis of variance models; (1) and (2) above yielded no unbiased simple linear functions that related observed variances (familieswithin-test $\left[\sigma_{F}^{2}\right]$, clones-within-families $\left.\left[\sigma_{C(F)}^{2}\right]\right)$ to genetic expectations. However, on examination of the algebraic expressions that relate observation to expectation (see Mullin and Park, 1992 and references therein for a clear presentation), we found it possible to establish useful bounds on estimates of genetic expectations.

Firstly, we considered the genetic expectation of the observed variance $\sigma_{F}^{2}$ (variance among full-sib families). Variance among full-sib families has long been known to result in the genetic expectation:

$2 \sigma_{\mathrm{F}}^{2}=1 \sigma_{\mathrm{A}}^{2}+1 / 2 \sigma_{\mathrm{D}}^{2}+1 / 2 \sigma_{\mathrm{AA}}^{2}+1 / 4 \sigma_{\mathrm{AD}}{ }^{2}+1 / 8 \sigma_{\mathrm{DD}}^{2}+1 / 4 \sigma_{\mathrm{AAA}}{ }^{2}-$.

The quantity $2 \sigma_{\mathrm{F}}{ }^{2}$ is, therefore, an upwardly biased estimate of additive genetic variance in the presence of dominance or epistatic effects. The coefficients decline as the equation (3) is expanded to the right, thus the bias becomes less strong as the order and complexity (number of loci involved) of epistatic interactions increase. We accepted the quantity $2 \sigma_{F}{ }^{2}$ as an upper bound of $\sigma_{A}{ }^{2}$ (additive genetic variance, $\sigma_{A}$ Upper ${ }^{2}$ ).

Secondly, we examined various simple linear combinations of genetic expectations and observed that the quantity $3 \sigma_{F}^{2}-\sigma_{C(F)}^{2}$ was useful for our purposes. Simple algebra demonstrated that the quantity yields the genetic expectation:

$$
3 \sigma_{\mathrm{F}}^{2}-\sigma_{\mathrm{C}(\mathrm{F})}^{2}=1 \sigma_{\mathrm{A}}^{2}+0 \sigma_{\mathrm{D}}^{2}+0 \sigma_{\mathrm{AA}}{ }^{2}-1 / 2 \sigma_{\mathrm{AD}}^{2}-3 / 4 \sigma_{\mathrm{DD}}^{2}-1 / 2 \sigma_{\mathrm{AAA}}{ }^{2}-
$$

The quantity $3 \sigma_{\mathrm{F}}{ }^{2}-\sigma_{\mathrm{C}(\mathrm{F})}{ }^{2}$ is, therefore, a downwardly biased estimate of additive genetic variance in the presence of epistatic effects but not dominance effects. The coefficients rise numerically as the equation is expanded to the right, thus bias becomes more negative as the order and complexity (number of loci involved) of epistatic interactions increase. We accepted the expression $3 \sigma_{F}{ }^{2}-\sigma_{C(F)}{ }^{2}$ as a lower bound of $\sigma_{A}{ }^{2}$ (additive genetic variance, $\sigma_{\mathrm{A} \mathrm{Lower}}{ }^{2}$ ) in our populations (Table 1).
Thus, while we were unable to formulate a point estimate of additive genetic variance, we were able to trap it, so to speak, within lower and upper bounds. Given this, variances due to non-additive effects became equally bounded by simple subtraction of $\sigma_{\mathrm{A} \text { Lower }}{ }^{2}$ or $\sigma_{\mathrm{A} \text { upper }}{ }^{2}$ from total genetic variance which we observed without statistical bias as $\sigma_{F}^{2}+\sigma_{C(F)}^{2}$.

We carried the examination of our data and the implications thereof somewhat further and questioned whether our observed variance components $\sigma_{\mathrm{F}}{ }^{2}$ and $\sigma_{\mathrm{C}(\mathrm{F})}{ }^{2}$ would be estimable in future work with reasonable precision under the logistical limitations to which our field testing is subjected. The rationale for our concern is that genetic variances might change over generations of breeding and selection and that monitoring of critical quantitative properties of our populations would necessitate modification of breeding and testing strategies.

Under balanced conditions, a variance component derived from the analysis of variance can be estimated by subtraction of one expected mean square from another (balanced experimental design) followed by suitable division by the trailing coefficient. The variances of the variance component for balanced designs are given in Comstock and Moll (1963), which we have expanded for our design.

Firstly, if the variance among clones is:

$$
\sigma_{c}^{2}=\left(M S_{c}-M S_{e}\right) / r
$$

then the variance of the clonal variance is estimated by:

$$
V_{\sigma_{c}^{2}}=\frac{1}{r^{2}}\left[\frac{2\left(\sigma_{e}^{2}+r \sigma_{c}^{2}\right)^{2}}{f(c-1)}+\frac{2\left(\sigma_{e}^{2}\right)^{2}}{f c(r-1)}\right]
$$

where $\sigma_{e}^{2}$ is observed variance among ramets within clones (experimental error), $\sigma_{c}^{2}$ is observed variance among clones, $f$ is number of families, $c$ is number of clones within each family, and $r$ is the number of ramets per clone.

Further, if the variance among families is:

$$
\sigma_{F}^{2}=\left(M S_{F}-M S_{C}\right) / r C
$$

then the variance of the family variance is estimated by:

$$
V_{\sigma_{f}^{2}}=\frac{1}{c r^{2}}\left[\frac{2\left(\sigma_{e}^{2}+r \sigma_{c}^{2}+r c \sigma_{f}^{2}\right)^{2}}{f-1}+\frac{2\left(\sigma_{e}^{2}+r \sigma_{c}^{2}\right)^{2}}{f(c-1)}\right]
$$

where $\sigma_{e}^{2}, \sigma_{c}^{2}, f, c$ and $r$ are as above, and $\sigma_{f}^{2}$ is the observed variance due to families.

Lastly, if $\sigma_{e}^{2}$ is variance among ramets within clones (experimental error), then the variance of error variance is estimated by:

$$
V_{\sigma_{e}^{2}}=\frac{2\left(\sigma_{e}^{2}\right)^{2}}{f c(r-1)}
$$

where all symbols are defined above. 


\section{Results}

All effects accounted for by our model were significant statistically $(p<0.0001)$ regardless of pedigree (Table 2$)$. Importantly, we note that the effects of imbalance in our experiments on expected mean square coefficients were small. Imbalance results in contributions of sources of variance to mean squares within which those sources would not appear given perfect balance. Yet, those offending coefficients, while non-zero, were mostly small and less than 1.0 (Table 1). Imbalance also results in a source of variation having differing coefficients depending on the mean square within which a source of variation appears. For example, the coefficient for variation due to clones-within-families would depend, under imbalance, on whether the term appears with the clone mean square or the family mean square. In our results, the coefficients did depend on mean square, but not greatly (Tables 2 and 3). Thus, we conclude that our statistical approach was appropriate.

\section{Table 1}

Genetic expectations of variance components and construction of expressions for upper and lower bounds for additive genetic variance.

\begin{tabular}{|c|c|c|c|c|c|c|c|c|c|}
\hline \multirow[b]{2}{*}{$\begin{array}{c}\text { Observed } \\
\text { Variance }\end{array}$} & \multirow[b]{2}{*}{$\sigma_{\mathrm{A}}^{2}$} & \multicolumn{8}{|c|}{ Genetic Expectation } \\
\hline & & $\sigma_{D}^{2}$ & $\sigma_{A A}^{2}$ & $\sigma_{A D}^{2}$ & $\sigma_{\mathrm{DD}}^{2}$ & $\sigma^{2}{ }_{A A A}$ & $\sigma_{A A D}^{2}$ & $\sigma_{\mathrm{ADD}}^{2}$ & $\sigma^{2} \mathrm{DDD}$ \\
\hline$\sigma_{F}^{2}$ & $1 / 2$ & $1 / 4$ & $1 / 4$ & $1 / 8$ & $1 / 16$ & $1 / 8$ & $1 / 16$ & $1 / 32$ & $1 / 64$ \\
\hline$\sigma_{C(F)}^{2}$ & $1 / 2$ & $3 / 4$ & $3 / 4$ & $7 / 8$ & $15 / 16$ & $7 / 8$ & $15 / 16$ & $31 / 32$ & $63 / 64$ \\
\hline $3 \sigma_{F}^{2}$ & $3 / 2$ & $3 / 4$ & $3 / 4$ & $3 / 8$ & $3 / 16$ & $3 / 8$ & $3 / 16$ & $3 / 32$ & $3 / 64$ \\
\hline $3 \sigma_{\mathrm{F}}^{2}-\sigma_{\mathrm{CF}}^{2}$ & 1 & 0 & 0 & $-1 / 2$ & $-3 / 4$ & $-1 / 2$ & $-3 / 4$ & $-7 / 8$ & $-15 / 16$ \\
\hline $2 \sigma_{F}^{2}$ & 1 & $1 / 2$ & $1 / 2$ & $1 / 4$ & $1 / 8$ & $1 / 4$ & $1 / 8$ & $1 / 16$ & $1 / 32$ \\
\hline
\end{tabular}

Expectations for variance among full sib families $\left(\sigma_{\mathrm{F}}^{2}\right)$ and variance among clones-within-families $\left(\sigma_{C(F)}^{2}\right)$ are taken from Mullin and Park (1992) where tabulated coefficients show the proportion of each source of genetic contributing to the observed variance estimate. We utilized the linear combinations $3 \sigma_{F}^{2}-\sigma_{C(F)}^{2}$ and $2 \sigma_{F}^{2}$ as lower and upper bounds, respectively, of $\sigma_{A}^{2}$ where departure of each bound from the unbiased point estimate depends on the strength of epistatic forms of genetic variation.

We did observe large differences in the distribution of variance due to error, among clones-within-families or among families, regardless of the pedigree of those populations. For example, variance attributable to clones-within-families was routinely about double the variance due to families for all intra- and inter-specific full-sib populations in our experiments (Table 4). Variance among clones was much greater (over 4X) than variance among families within our population of $P$. nigra (Table 4). This was, however, completely expected because our P. nigra families were open-pollinated seed collected from natural stands across Europe. The full-sib families would have an expected $50 \% / 50 \%$ distribution of additive genetic variance among and within families (Table 5), versus an expected $25 \%$ / $75 \%$ ratio for the same distribution for the presumably half-sib families (Table 6). Distribution of variances when corrected for
Table 2

Form and results of analyses of variance used to evaluate the structure of variances among and within families and clones.

$\begin{array}{cccc} & \text { Degrees of } & \text { Mean } & \\ \text { Source of Variation } & \text { Freedom } & \text { Square } & \text { Expected Mean Square }\end{array}$

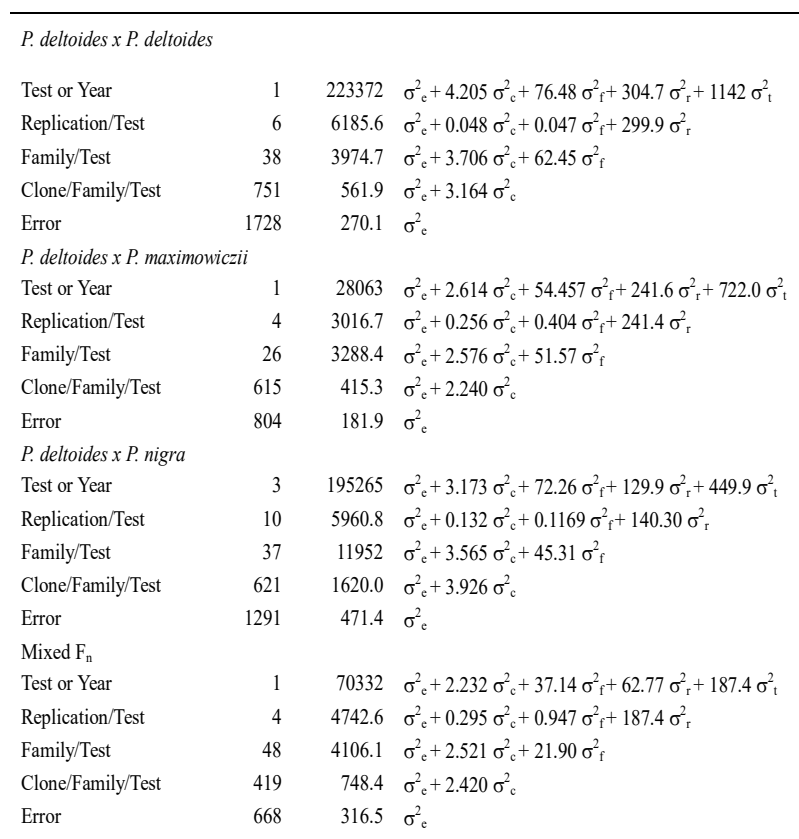

Each pedigree type was represented at, minimally, two locations. Data were analyzed using SAS Proc GLM specifying Type I mean squares and expected mean squares. All mean squares were statistically significant by $f$-test $(p<0.01$ or less).

Table 3. Form and results of analyses of variance used to evaluate the structure of variances among and within families and clones of new Populus nigra collections.

\begin{tabular}{|c|c|c|c|}
\hline & Degrees of & Mean & \\
\hline Source of Variation & Freedom & Square & Expected Mean Square \\
\hline Family & 14 & 4652.8 & $\sigma_{\mathrm{e}}^{2}+1.846 \sigma_{\mathrm{c}}^{2}+48.19 \sigma_{\mathrm{f}}^{2}$ \\
\hline Clone/family & 393 & 1173.7 & $\sigma_{e}^{2}+1.782 \sigma_{c}^{2}$ \\
\hline Error & 320 & 628.9 & $\sigma_{\mathrm{e}}^{2}$ \\
\hline
\end{tabular}

Data were analyzed using SAS Proc GLM specifying Type I mean squares and expected mean squares.

scale, such as among- and within-families as a percentage of total variation, was surprisingly invariant among various populations regardless of pedigree (Table 6).

We also devoted substantial analytical attention to the precision with which variance components attributable to model-specified effects would be made in balanced experiments, should those components equal our current results (Table 6). We estimated that the standard deviation of the variance attributable to family effects would range from $20 \%$ to about $23 \%$ of the variance component regardless of whether data were examined on a location by location basis (Table 5) or on a pedigree basis (Table 6). Corresponding estimated 
standard deviations of clone-within-family variance would range from $5 \%$ to about $9 \%$, and error variance would be stable at little more than $2 \%$ (Table 6 ). The stability of precision with which an error variance is estimated is unsurprising, given an invariant hypothetical experimental design, because under such conditions the variance of error variance is a function only of error.

Table 4

Derived estimates of observed variance components for basal area.

\begin{tabular}{|c|c|c|c|c|}
\hline Estimate & $\begin{array}{l}\text { P. deltoides } x \\
\text { P. deltoides }\end{array}$ & $\begin{array}{l}\text { P. deltoides } x \\
\text { P. maximowiczii }\end{array}$ & $\begin{array}{l}\text { P. deltoides } x \\
\text { P. nigra }\end{array}$ & P. nigra \\
\hline Family variance & 53.8 & 55.0 & 222.5 & 71.8 \\
\hline Clone/family variance & 92.2 & 104.2 & 392.6 & 305.7 \\
\hline Environmental variance & 270.1 & 181.9 & 471.4 & 628.9 \\
\hline Total genetic variance & 146.1 & 158.2 & 615.1 & 377.5 \\
\hline Additive (lower limit) & 69.3 & 60.9 & 274.9 & 287.2 \\
\hline Additive (upper limit) & 107.7 & 110.1 & 443.0 & \\
\hline Non-additive (lower limit) & 38.4 & 48.1 & 172.1 & 90.3 \\
\hline Non-additive (upper limit) & 76.8 & 97.3 & 340.2 & \\
\hline Phenotypic variance & 416.2 & 340.1 & 811.6 & 1006.4 \\
\hline Lower limit narrow-sense heritability & 0.166 & 0.179 & 0.339 & 0.285 \\
\hline Upper limit narrow-sense heritability & 0.259 & 0.324 & 0.546 & \\
\hline $\begin{array}{l}\text { Phenotypic variance of the family mean } \\
(\mathrm{n}=20, \mathrm{r}=4)\end{array}$ & 61.8 & 62.5 & 248.0 & 118.5 \\
\hline $\begin{array}{l}\text { Phenotypic variance of the clone mean } \\
(\mathrm{r}=4)\end{array}$ & 200.1 & 189.2 & 709.4 & 534.7 \\
\hline $\begin{array}{l}\text { Lower limit narrow-sense heritability of } \\
\text { family mean }\end{array}$ & 0.561 & 0.487 & 0.554 & 0.606 \\
\hline $\begin{array}{l}\text { Upper limit narrow-sense heritability of } \\
\text { family mean }\end{array}$ & 0.871 & 0.881 & 0.893 & \\
\hline Broad-sense heritability & 0.351 & 0.465 & 0.758 & 0.375 \\
\hline $\begin{array}{l}\text { Broad-sense heritability of clone mean } \\
(\mathrm{r}=5)\end{array}$ & 0.730 & 0.836 & 0.867 & 0.706 \\
\hline Population mean & 58.49 & 32.90 & 63.80 & 58.80 \\
\hline $\begin{array}{l}\text { Lower limit additive response to among } \\
\text { and within family selection ( } 1 \text { in } 10 \\
\text { each, } n=20, r=5 \text { ) }\end{array}$ & $10.24(17.5 \%)$ & & & $7.88(47.4 \%)$ \\
\hline $\begin{array}{l}\text { Upper limit additive response to among } \\
\text { and within family selection ( } 1 \text { in } 10 \\
\text { each, } n=20, r=5 \text { ) }\end{array}$ & $15.92(27.2 \%)$ & & & \\
\hline $\begin{array}{l}\text { Broad-sense response to clonal selection } \\
(1 \text { in } 100, r=5)\end{array}$ & & $29.63(90.1 \%)$ & $59.50(93.3 \%)$ & \\
\hline
\end{tabular}

Upper and lower bounds for additive and non-additive genetic variances, and expected additive or broad-sense response to selection (according to our proposed testing and selection strategy) for pure species of Populus and their interspecific progeny. P. nigra families were half-sib (OP), all other families were full sib.

Table 5

Theoretical variances and standard deviations of variance components for basal area due to families, clones-within-families and ramets within clones (experimental error) for each location (as defined by year) in our testing environment.

\begin{tabular}{|c|c|c|c|c|c|c|}
\hline $\begin{array}{l}\text { Source of } \\
\text { Variation }\end{array}$ & $\begin{array}{l}\text { Hypothesized } \\
\text { future df }\end{array}$ & $\begin{array}{l}\text { Variance } \\
\text { Component } \\
\text { Estimate }\end{array}$ & $\begin{array}{c}\text { Percent of } \\
\text { Phenotypic } \\
\text { Variance }\end{array}$ & $\begin{array}{l}\text { Variance } \\
\text { of } \\
\text { Estimate }\end{array}$ & $\begin{array}{l}\text { Standard } \\
\text { Deviation }\end{array}$ & $\begin{array}{c}\mathrm{SD} \\
\text { (percent) }\end{array}$ \\
\hline \multicolumn{7}{|l|}{2001 Test } \\
\hline $\begin{array}{l}\text { Families } \\
\text { Clones-within- }\end{array}$ & 49 & 156.61 & $31.69 \%$ & 1066.36 & 32.66 & $20.85 \%$ \\
\hline $\begin{array}{l}\text { families } \\
\text { Error }\end{array}$ & $\begin{array}{l}1950 \\
4000\end{array}$ & $\begin{array}{l}132.55 \\
205.11\end{array}$ & $\begin{array}{l}26.82 \% \\
41.50 \%\end{array}$ & $\begin{array}{l}62.44 \\
21.04\end{array}$ & $\begin{array}{l}7.90 \\
4.59\end{array}$ & $\begin{array}{l}5.96 \% \\
2.24 \%\end{array}$ \\
\hline \multicolumn{7}{|l|}{2002 Test } \\
\hline Families & 49 & 162.66 & $25.74 \%$ & 1169.44 & 34.20 & $21.02 \%$ \\
\hline $\begin{array}{l}\text { Clones/families } \\
\text { Error }\end{array}$ & $\begin{array}{l}1950 \\
4000\end{array}$ & $\begin{array}{l}161.53 \\
307.84\end{array}$ & $\begin{array}{l}25.56 \% \\
48.71 \%\end{array}$ & $\begin{array}{c}118.94 \\
47.38\end{array}$ & $\begin{array}{l}10.91 \\
6.88\end{array}$ & $\begin{array}{l}6.75 \% \\
2.24 \%\end{array}$ \\
\hline \multicolumn{7}{|l|}{2007 Test } \\
\hline Families & 49 & 397.74 & $33.35 \%$ & 6869.10 & 82.88 & $20.84 \%$ \\
\hline Clones/families & 1950 & 351.95 & $29.51 \%$ & 354.16 & 18.82 & $5.35 \%$ \\
\hline Error & 4000 & 443.02 & $37.14 \%$ & 98.13 & 9.91 & $2.24 \%$ \\
\hline \multicolumn{7}{|l|}{2008 Test } \\
\hline Families & 49 & 198.83 & $28.51 \%$ & 1724.06 & 41.52 & $20.88 \%$ \\
\hline Clones/families & 1950 & 152.15 & $21.82 \%$ & 133.41 & 11.55 & $7.59 \%$ \\
\hline
\end{tabular}

Estimates utilize our observed variance components applied to hypothetically balanced tests consisting of 50 families, 40 clones within each family and each clone replicated three times (ramets within clone). The actual tests were 40 fullsib families of $P$. deltoides $x$ P. deltoides, 28 full-sib families of $P$. deltoides $x P$. maximowiczii, 41 full-sib families of $P$. deltoides $x$ P. nigra, and 40 full-sib families of various $F_{2}$ and first-generation backcross advanced-generation pedigrees.

Table 6

Theoretical variances and standard deviations of variance components for basal area by population pedigree.

\begin{tabular}{|c|c|c|c|c|c|c|}
\hline Source of Variation & $\begin{array}{l}\text { Hypothesized } \\
\text { future } \\
\text { df }\end{array}$ & $\begin{array}{c}\text { Variance } \\
\text { Component } \\
\text { Estimate }\end{array}$ & $\begin{array}{c}\text { Percent of } \\
\text { Phenotypic } \\
\text { Variance }\end{array}$ & $\begin{array}{c}\text { Variance } \\
\text { of } \\
\text { Estimate }\end{array}$ & $\begin{array}{c}\text { Standard } \\
\text { Deviatio } \\
\mathrm{n}\end{array}$ & $\begin{array}{c}\text { SD } \\
\text { (percent) }\end{array}$ \\
\hline \multicolumn{7}{|c|}{$P$. deltoides $x$ P. deltoides } \\
\hline Families & 49 & 53.8 & $12.93 \%$ & 139.02 & 11.79 & $21.92 \%$ \\
\hline Clones/families & 1950 & 92.2 & $22.16 \%$ & 70.54 & 8.40 & $9.11 \%$ \\
\hline Error & 4000 & 270.1 & $64.91 \%$ & 36.48 & 6.04 & $2.24 \%$ \\
\hline \multicolumn{7}{|c|}{ P. deltoides $x$ P. maximowiczii } \\
\hline Families & 49 & 55 & $16.12 \%$ & 142.68 & 11.94 & $21.72 \%$ \\
\hline Clones/families & 1950 & 104.2 & $30.55 \%$ & 44.41 & 6.66 & $6.40 \%$ \\
\hline Error & 4000 & 181.9 & $53.33 \%$ & 16.54 & 4.07 & $2.24 \%$ \\
\hline \multicolumn{7}{|l|}{ P. deltoides $x$ P. nigra } \\
\hline Families & 49 & 222.5 & $20.48 \%$ & 2278.19 & 47.73 & $21.45 \%$ \\
\hline Clones/families & 1950 & 392.6 & $36.13 \%$ & 421.06 & 20.52 & $5.23 \%$ \\
\hline Error & 4000 & 471.4 & $43.39 \%$ & 111.11 & 10.54 & $2.24 \%$ \\
\hline \multicolumn{7}{|l|}{ P. nigra } \\
\hline Families & 49 & 71.8 & $7.13 \%$ & 292.88 & 17.11 & $23.84 \%$ \\
\hline Clones/families & 1950 & 305.7 & $30.38 \%$ & 470.14 & 21.68 & $7.09 \%$ \\
\hline Error & 4000 & 628.9 & $62.49 \%$ & 197.76 & 14.06 & $2.24 \%$ \\
\hline
\end{tabular}

Estimates utilize our observed variance components applied to hypothetically balanced tests consisting of 50 families, 40 clones within each family and each clone replicated three times (ramets within clone). P. nigra families were half-sib $(\mathrm{OP})$, all other families were full sib.

\section{Discussion}

Our long-standing goal in this work has been to obtain sufficient knowledge of the kinds and distribution of various genetic variances that relate to the rational design of a long-term hybrid poplar breeding program that maximizes yield gain in the most efficient manner possible. Due to the fact that additive variance is proven to be non-zero in these populations, our results indicate that a breeding strategy consisting of intraspecific recurrent selection applied to populations of at least two pure species would be effective.

In our case, the populations of greatest interest are $P$. deltoides and P. nigra. Select individuals from these recurrently improved populations would be hybridized to produce $F_{1}$ hybrid populations. The resulting families would be subjected to multiple replicated field tests, and clones with valuable commercial traits selected for further field testing. Advanced-generation breeding derived from the $F_{1}$ would not be pursued, because the $F_{2}$ and subsequent hybrid generations are expected to yield too high a frequency of maladapted types. Also, our experience has shown a significant reduction in fertility and fecundity to the point of impracticality. Inbreeding due to finite (small) population sizes of the parental populations would not be troubling, because any such inbreeding would be relieved though the subsequent process of interspecific hybridization.

This strategy has been previously hypothesized (Bisoffi and Gullberg, 1996; Riemenschneider et al., 2001) along with many other strategies. Yet, our ability to determine an 
optimum strategy, or even to evaluate the effectiveness of any single possibility, has remained elusive because knowledge of the amounts of additive and non-additive genetic variances in our selection and response criterion, tree volume or weight, have been unavailable. While it is impossible to fully know the extent to which our results can be applied, our work indicates a clear path forward for poplar breeding. For example, we found narrow-sense heritability for tree basal area within our populations to lie between 0.166 (lower bound) and 0.259 (upper bound) while our point estimate of the same parameter within our P. nigra population was 0.285 (Table 4). Heritability of corresponding family means would be substantially higher under even modest replication (Table 4) which suggests to us that some form of combined family and mass selection, such as an index-based calculation, would lead to increases in growth rate of $27 \%$ and $47 \%$ per generation in P. deltoides and P. nigra, respectively (Table 4). Broad sense-based clonal selection within the F1 could yield selection responses in excess of $90 \%$ of the mean of such populations (Table 4). Taken together, our results support the assertion that recurrent intraspecific selective breeding followed by interspecific hybridization and nonrecurrent selection based on broad-sense genetic variation would constitute an effective improvement strategy.

Our method of estimating additive genetic variance in tree basal area, which yielded upper and lower bounds but not point estimates within intra-specific $P$. deltoides and $F_{1}$ hybrid populations, has not previously been used in tree genetics research. We chose to apply an analysis of variance model that included sources of variation due only to full-sib families, clones-within-families, and ramets-within-clones. While a full factorial model that includes male parents, female parents and the male $x$ female interaction may be ideal (White et al., 2007), the biological realties of incompatibilities within a fully-saturated breeding matrix make this an untenable approach. Incompatibilities of specific crosses would require multiple attempts using the same parents at considerable expense in time and money and limit the genetic diversity of the overall program. Our controlled breeding technique (greenhouse plant-in-pot breeding using rooted female bud-bearing branches) yielded viable seed of full-sib families at a rate between $40 \%$ and $65 \%$ of crosses attempted. The resulting imbalanced parent-progeny array, when a more complete model was fitted, yielded results that were often recalcitrant in the face of least-squares analysis of variance methods and available software, or results that were uninterpretable. The option of focusing on a small subset of our tested populations to achieve analysis of a smaller, fully balanced design and model such as the one presented by Foster and Shaw (1988) was considered, but this option was rejected because the smaller subset might not have been representative (not constituted an unbiased random sample) of our full series of experimental observations. Furthermore, we anticipate that profound imbalance would be characteristic of any future breeding program and that no realistic effort on our part, considering the demand for practical progress and likely logistical limitations, would yield any improved analytical opportunities. We contend that our chosen system of estimation using various linear combinations of genetic expectations (Table 1) among and between full-sib families that yielded only bounded estimates was appropriate given both our current needs and future limitations.

We also considered the precision with which we might estimate variances due to families, clones-within-families and ramets-within-clones in any future work assuming equal family size, equal clonal replication and reasonable logistics under our current analytical model. We therefore estimated the variances and standard deviations of the above stated variance components by using our currently observed estimates, reconstructing appropriate mean squares assuming balanced experiments and applying the early methods of Comstock and Moll (1963). Our results demonstrate that standard deviations of estimated variances would range from $2 \%$ to $3 \%$ for variances among ramets to only $20 \%$ for variances attributable to families (Tables 5 and 6). Interestingly, anticipated estimation precision based on current observation and assumed future balance would be largely invariant with regard to test location (Table 5) or population pedigree (Table 6). Thus, it is plausible to anticipate that any changes in observed sources of variation attributable to multi-generation effects of selective breeding could be readily monitored and necessary adjustments in population size or experimental design could be made.

Our final discussion point has to do with the distribution of among-family versus within-family variance estimates when comparisons are made among our $P$. deltoides and two $F_{1}$ hybrid populations (Table 4). Among-family variance was always about $1 / 3$ of total genetic variance while within-family variance was always about $2 / 3$ of total genetic variance regardless of the species origin of the parents (Table 4). The generally accepted taxonomic groupings of poplars (see Eckenwalder, 1996 and references therein) render our results unexpected. For example, our $P$. deltoides parents would, at the most, have been separated by geographic isolation and resultant genetic divergence only after the most recent glacial retreat from Minnesota ( $10^{4}$ years). Geographic isolation of $P$. deltoides from $P$. nigra would have been caused, presumably, by plate tectonics and the opening of the Atlantic rift ( $10^{8}$ years). Isolation of $P$. deltoides from $P$. maximowiczii, an Asian species, would have presumably been of even longer duration, and the genetic distance between the two species further increased by their divergence into different taxonomic sections within the genus Populus (Eckenwalder, 1996). We fully expected that genetic divergence among and within species would have resulted in substantially different distributions of genetic variance among and within-families for each species, and thus differences in the relative strengths of additive and non-additive genetic effects. Such a result would have suggested that optimal mating designs and the designs of subsequent field tests would have been population-dependent which would necessarily complicate future work; but, we observed the opposite. Our results suggest that a program of domestication and breeding based on intra- and inter-specific hybridization of Minnesota $P$. deltoides could adopt a single optimum strategy applicable to all populations regardless of ancestry.

Conclusions can be summarized as follows. We have tested several species of Populus and their $\mathrm{F}_{1}$ inter-specific hybrids for several years at four test locations in Minnesota, USA. The scope of inference of our results and conclusions may be 
constrained due to the limited geographic range of our P. deltoides parents. Yet, within that range we found that both additive and non-additive genetic effects on tree basal area growth were substantial. Given our large sample size, we consider our results to be reliable and descriptive of any future work subject to the same limitations on scope of inference. Our results suggest that recurrent selection applied to populations of pure species would be effective due to narrow-sense genetic response to selection. Further, our results suggest that selection among F1 clones derived from recurrently selected parental species would result in substantial additional genetic response due to clonal (broad-sense) variances. Also, our observation that the ratio of additive to non-additive genetic variances was mostly invariant among pedigrees suggests that one optimized breeding, testing and selection strategy could be used in all cases. In sum, we found strong support for pursuing a sophisticated recurrent breeding and selection program as has been previously hypothesized (Bisoffi and Gullberg, 1996; Riemenschneider et al., 2001). Both additive and non-additive sources of genetic variation are substantial and, in combination with our ability to deploy large populations which support high selection intensities, should result in a significant increase in yield with each breeding cycle.

\section{Acknowledgement}

This work was funded by the State of Minnesota appropriations to the Minnesota Hybrid Poplar Research Cooperative (MHPRC), State Special appropriations to the University of Minnesota Duluth Natural Resources Research Institute, Minnesota Agricultural Utilization Research Institute, U.S. DOE BETO Sun Grant Initiative Poplar Woody Crops Program contract \# DEFC36-05G085041, and the following companies through membership in the MHPRC - Verso Corporation, International Paper, Boise Cascade, Potlatch Corporation, UPM-Blandin, and Minnesota Power. The authors acknowledge and thank Verso Corporation's forestry staff for providing land and assistance with site selection, planting and maintenance throughout the field testing periods of these trials. Neil Nelson, Ph.D., is acknowledged for final technical review and edits and Neil Nelson and Kim Rewinkel for finalizing the paper for journal submission.

\section{References}

Bisoffi S and U Gullberg (1996) Poplar breeding and selection strategies. In: Stettler RF, HD Bradshaw Jr, PE Heilman and TM Hinckley (eds) Biology of Populus and its implications for management and conservation. Ottawa, ON, Canada: NRC Research Press, National Research Council of Canada, pp 139158, ISBN 0-660-16506-6

Comstock RE and RH Moll (1963) Genotype - environment interactions. In: Hanson WD and HF Robinson (eds) Statistical genetics and plant breeding. Publication 982. Washington, DC, USA: National Academy of Sciences, National Research Council, pp 164-196

Eckenwalder JE (1996) Systematics and evolution of Populus. In: Stettler RF, HD Bradshaw Jr, PE Heilman and TM Hinckley (eds) Biology of Populus and its implications for management and conservation. Ottawa, ON, Canada: NRC
Research Press, National Research Council of Canada, pp 7-32, ISBN 0-66016506-6

Foster GS and DV Shaw (1988) Using clonal replicates to explore genetic variation in a perennial plant species. Theoretical and Applied Genetics 76:788794. https://doi.org/10.1007/BF00303527

Hansen EA, ME Ostry, WD Johnson, DN Tolsted, DA Netzer, WE Berguson and RB Hall (1994) Field performance of Populus in short-rotation intensive culture plantations in the north-central U.S. Research Paper NC-320. St. Paul, MN, USA: U.S. Department of Agriculture, Forest Service, North Central Forest Experiment Station, 13 p. https://doi.org/10.2737/nc-rp-320

Libby WJ (1982) What is a safe number of clones per plantation? In: Resistance to disease and pests in forest trees. Proceedings of Third International Workshop on the Genetics of Host-Parasite Interactions in Forestry. Wageningen, The Netherlands, September 1980, pp 342-360

Miller RO (2016) Final report: regional feedstock partnership - poplar in Michigan. Michigan State University Forest Biomass Innovation Center Research Report 2016(h), $24 \mathrm{p}$

Mullin TJ and YS Park (1992) Estimating genetic gains from alternative breeding strategies for clonal forestry. Canadian Journal of Forest Research 22:14-23. https://doi.org/10.1139/x92-003

Netzer DA, DN Tolsted, ME Ostry, JG Isebrands, DE Riemenschneider and KT Ward (2002) Growth, yield, and disease resistance of 7- to 12-year-old poplar clones in the north central United States. General Technical Report NC229. St. Paul, MN, USA: U.S. Department of Agriculture, Forest Service, North Central Research Station, 31 p. https://doi.org/10.2737/nc-gtr-229

Riemenschneider DE, BJ Stanton, G Vallée and P Périnet (2001) Poplar breeding strategies. In: Dickmann DI, JG Isebrands, JE Eckenwalder and J Richardson (eds) Poplar culture in North America. Ottawa, ON, Canada: NRC Research Press, National Research Council of Canada, pp 43-76, ISBN 0-660-18145-2 Roberds JH, G Namkoong and T Skrøppa (1990) Genetic analysis of risk in clonal plantations of forest trees. Theoretical and Applied Genetics 79:841-848. https://doi.org/10.1007/BF00224254

SAS Institute, Inc. (2004) SAS/STAT ${ }^{\circ} 9.1$ User's Guide. Cary, NC: SAS Institute. Stettler RF, HD Bradshaw Jr and L Zsuffa (1992) The role of genetic improvement in short rotation forestry. In: Mitchell CP, JB Ford-Robertson, T Hinckley and L Sennerby-Forsse (eds) Ecophysiology of short rotation forest crops. London, UK: Elsevier Applied Science, pp 285-308, ISBN 1-85166-848-9

White TL, WT Adams and DB Neale (2007) Forest genetics. Wallingford, Oxfordshire, UK: CABI Publishers, pp 113-148, 357-393, ISBN-13: 978-1-84593-2855

Ying CC and WT Bagley (1977) Variation in rooting capability of Populus deltoides. Silvae Genetica 26(5-6):204-207

Zalesny, Jr. RS, DE Riemenschneider and RB Hall (2005) Early rooting of dormant hardwood cuttings of Populus: analysis of quantitative genetics and genotype $x$ environment interactions. Canadian Journal of Forest Research 35:918-929. https://doi.org/10.1139/x05-018

Zobel B and J Talbert (1984) Applied forest tree improvement. New York, NY, USA: John Wiley \& Sons, Inc, pp 309-344, ISBN 0-471-09682-2 